\title{
Analecta Veterinaria en tiempos de pandemia
}

ANALECTa Veterinaria, órgano oficial de comunicación científica de la Facultad de Ciencias Veterinarias de la Universidad Nacional de La Plata, ya ha cumplido 115 años desde su creación, con el nombre de "Revista de la Facultad de Agronomía y Veterinaria de La Plata", y 50 años desde la instauración de su actual denominación. Hoy, como antaño, Analecta Veterinaria se compromete con el saber científico en el área de las ciencias veterinarias, sea este correspondiente a conocimientos básicos, como aquellos que se relacionan con las prácticas clínicas, la producción agropecuaria y los alimentos destinados al consumo humano y animal.

La pandemia del COVID-19 ha golpeado, en mayor o en menor medida, sobre cada puerta de nuestro planeta y ha cambiado, en poco tiempo, muchos de los aspectos de nuestras vidas. Las prácticas profesionales se han visto reducidas y los laboratorios de investigación prácticamente están cerrados. Ante esta situación, los resultados que se puedan obtener en los próximos meses surgirán, mayoritariamente, del análisis de los datos obtenidos con anterioridad a la declaración de la pandemia o de los que obtengan aquellos grupos beneficiados a través de los subsidios otorgados por organismos gubernamentales o privados para afrontar la situación epidemiológica.

A partir de todo evento desafortunado surgen las ideas más brillantes para sobrellevarlo y esta pandemia no está exenta de ese principio. Día a día se leen artículos en revistas científicas que proponen nuevos o antiguos tratamientos para combatir al coronavirus. Con una celeridad nunca antes vista estamos conociendo nuevos aspectos de la enfermedad y diferentes grupos de investigadores de diferentes partes del mundo se aúnan para potenciar sus conocimientos. Sin embargo, es tiempo de ser responsables. Es fundamental que los resultados que se pretendan publicar hayan sido científicamente consolidados bajo las estrictas normas del método científico y los estándares de la ética que la situación requiere. Generar conocimiento científico es un proceso lento y tedioso, el que finalmente requiere del rigor de la aceptación por parte de pares.

Desde ANALECTA VETERINARIA instamos a seguir trabajando en beneficio de la ciencia, cada uno en su área específica, dando lo mejor de sí. La pandemia del coronavirus es coyuntural, aún no ha finalizado o su final es incierto, pero nos dejará una enseñanza: debemos estar preparados científicamente para afrontar cualquier situación emergente.

Consejo Editorial

ANALECTA VETERINARIA

ANALECTA VET 2019; Enero-Junio; 4O(1):1

Impresa ISSN 03655 14-8 Electrónica ISSN 1514-2590

doi.org/10.24215/15142590eo43 